\title{
EJRR Special Issue Editorial: COVID-19 and Soft Law: Is Soft Law Pandemic-Proof?
}

\author{
Mariolina ELIANTONIO*, Emilia KORKEA-AHO** and Steven VAUGHAN***
}

\section{INTRODUCTION}

COVID-19 has been an unprecedented challenge to many legal systems around the world. In attempting to mitigate the devastating social, economic and political effects of the virus, governments have closed national borders, schools, cinemas and restaurants, ordered lockdowns, strongly recommended that those over 70 years old stay indoors in quarantine-like conditions, banned social gatherings, and encouraged social distancing and the use of face masks.

In addition to "normal" legislative measures (or, in some legal systems, administrative rule-making in the form of governmental or ministerial decrees), much of the regulation of COVID-19 has taken place through circulars, instructions, guidance and other soft law norms, the legal status of which is not entirely clear. The articles in this Special Issue focus on the use of such non-binding soft law guidance in dealing with COVID-19 in a comparative perspective.

To what extent have national governments and other (central or local) authorities used non-binding soft law guidance - in addition to or instead of binding rules - to stop or to slow down the spread of the virus? To what extent has soft law been used to restrict fundamental and human rights (beyond what was foreseen in binding rules)? If soft law has been used in such a way, have public authorities overstepped constitutional and legal limits? How have courts, lawyers and the public responded to soft law guidance?

Reflecting on these questions, the articles contained in this Special Issue compare and critically analyse the uses of soft law in dealing with COVID-19 at EU level, as well as in seven EU Member States (Finland, Germany, Greece, Hungary, Italy, Spain, Sweden), China and England. We have chosen to focus on these ten legal systems because of the various ways in which the pandemic has impacted them: while China was the first country to be hit, it was soon followed in Europe by Italy and, within only a few weeks, also by other European countries. ${ }^{1}$ Furthermore, these countries have followed very different approaches to the management of the pandemic, ranging from a full lockdown in China, Italy and Spain to very mild recommendations in Sweden. These differences

\footnotetext{
* University of Maastricht, The Netherlands; email: m.eliantonio@maastrichtuniversity.nl.

** University of Eastern Finland, Finland; email: emilia.korkea-aho@uef.fi.

****University College London, UK; email steven.vaughan@ucl.ac.uk.

1 For COVID-19 data (both past and up to date), see European Centre for Disease Prevention and Control $<$ www. ecdc.europa.eu/en/covid-19/data> accessed 11 December 2020.
} 
have not only resulted from different legal and political traditions (such as federalism in Germany) but the countries' specific approaches also reflected the particular circumstances they were facing locally (such as the large number of migrants in Greece).

The task that we guest editors asked our contributors to perform has not been an easy one. There are always risks with this sort of action research. The first is that temporal closeness to the events being analysed precludes the objectivity and distance that come with the passing of time. Would we, and our contributors, say different things were we to have written these papers two, three (etc) years from now? Perhaps. The second is that it is almost impossible to be "current" and on top of things; that is, it is almost certain that various things that are described in what follows no longer exist (or look wildly different) because we are still in the throes of the pandemic and governments, agencies and others are still playing with their regulatory response mixes. This is perhaps no bad thing when it comes to soft law: as many of our contributors lament, accessing COVID-19 soft law on official websites is somewhat a matter of luck (with those norms being removed or amended; and finding older or deleted versions a challenge). As a result, what the articles in this Special Issue provide is a snapshot of soft law practices at a particular moment in time. Our temporal focus is the period of March-August 2020, to which the research (as well as media outlets) generally refers as "the first wave". Other scholars can, if they so wish, build on this work in the future. The task our contributors have faced has been a challenging one in another respect, as well. As editors, we decided not to provide any general explanation of the theoretical assumptions inherent in the soft and hard law regulation tools and their use in the emergency context for the authors to build on. This is because we feel that this discussion is peculiar to each legal system, and each article in this Special Issue unfolds a unique - yet at the same time universal - story of how COVID19 soft law is both important per se (in that how governments use law, of various forms, to respond to the pandemic matters) and as a lens through which to view ongoing debates about the functions, purposes and aims (and so on) of soft law as a means of governance in modern democracies.

\section{The use of soft law as a tool to manage the COVID-19 pandemic: between different national cultures, shady procedure and uncertain perceptions}

The ten articles in this Special Issue cover a lot of ground. This is intentional. As noted above, what follows are insights into the use of soft law as a regulatory tool to respond to COVID-19 in China, England, Finland, Germany, Greece, Hungary, Italy, Spain, Sweden, and by the EU itself. Some of these papers are "state of the nation" accounts of COVID-19 soft law and their aim is to sketch a map of the place of soft law in that country's legal order and to explore the soft law that has been created as a response to the pandemic. Others take deeper dives into particular issues or legal fields within their own jurisdictions linked to COVID-19: the paper on Italy looks at freedom of worship and freedom of economic enterprise; that on Hungary covers primary education; that on Finland speaks to border traffic; that on England addresses the criminal justice system; and that on Greece explores COVID-19 controls on asylum seekers, data protection, criminal sanctions and free movement. 
Perhaps unsurprisingly, there was no consistency across the EU Member States, China and England in the use of soft law as a regulatory response to COVID-19. We see regional variations on micro and macro scales. So, for example, the approach in Sweden differs from the approach adopted in its Nordic neighbours, Denmark, Finland, Iceland and Norway. We also see places in which COVID-19 soft law was used widely (Sweden, Spain, England, the EU) and places where it was hardly used at all (Greece) or used minimally (Germany). Of the former, in Spain there were more than 200 non-binding measures adopted by the state and the 17 regional Autonomous Communities between March and July 2020. And in England there are perhaps as many as 400 guidance documents (of various types) that have been created in response to the pandemic. The EU had also issued 197 soft law instruments linked with COVID-19 up to August 2020. By contrast, in Greece COVID-19 hard law ("acts of legislative content") far outweighed the corresponding soft law instruments. Or consider China, which has, thanks to the legacy of the SARS epidemic in 2003, "a relatively complete hard law framework to combat infectious diseases". 2 Yet it soon found out that the hard law framework was insufficient to cope with the challenge of the COVID-19 epidemic and opted to issue soft law to complement hard law. We also see the deployment of soft law having a temporal element: in Italy, for example, soft law was only really used in Phase II of the country's COVID-19 response (from May 2020 onwards). As in other times and in other ways, these papers show a wide variety of soft instruments being deployed: General Recommendations, Protocols, Guidance, Guidelines, Technical Recommendations, Circulars, FAQs, Pandemic Plans, Administrative Directions, Codes of Conduct and so on.

It seems that the variations in practices covered by these articles speak both to practical differences in the approaches taken by different governments (and the extent to which those governments "listened to the science") but also on a more fundamental level to the underlying legal orders in each of the jurisdictions in which we are interested. That is, to what extent is the use of COVID-19 reflective of, and/or resistant to, the underlying legal culture of each jurisdiction? In Sweden, for example, "the lack of constitutional distinction between the roles of the legislative and executive powers may account for the wide scope for leaving the task of adopting both binding and non-binding rules to the Public Health Agency". 3 Or does the avalanche of soft law in England reflect the fact that soft law has been "an integral part of the efficient and effective functioning of public administration in England \& Wales"? ${ }^{4}$

The articles in this Special Issue also highlight differences in addressees: soft law instruments that are addressed to all citizens; those that impact only certain regions or places; and those that speak to certain sectors or industries. There is, as far we can see, no pattern to the (un)evenness with which soft law is deployed to respond to

2 X Cheng, "Soft Law in the Prevention and Control of the COVID-19 Pandemic in China: Between Legality Concerns and Limited Participatory Possibilities" (2021) European Journal of Risk Regulation <DOI:10.1017/err.2020.111>.

3 H Wenander, "Sweden: Non-binding Rules against the Pandemic - Formalism, Pragmatism and Some Legal Realism" (2021) European Journal of Risk Regulation <DOI:10.1017/err.2021.2>.

4 J Sorabji and S Vaughan, “'This Is Not A Rule’: COVID-19 in England \& Wales and Criminal Justice Governance via Guidance” (2021) European Journal of Risk Regulation <DOI:10.1017/err.2020.118>. 
COVID-19. And so, at the EU level for example, in "sectors such as competition and state aid, the consequences of the health crisis were dealt with exclusively through soft law". 5

Our Special Issue articles also highlight differences in whether COVID-19 soft law was "business as usual" (ie whether soft law was used in similar ways to respond to the current pandemic as it had been previously in other ways - see here the papers on Germany and England) or whether something new was going on. In Spain, for example, soft law has historically only been (generally) used to guide the conduct of administrative bodies. With the pandemic, Spain has used soft law to speak to and guide the public in a much more substantive fashion. The same is true of Hungary, where Láncos and Christián say that the use of COVID-19 soft law marks a "milestone in Hungarian administrative regulatory behaviour, since beyond instances of internal guidance, non-binding measures have hitherto hardly played a role in national administrative governance". 6 And in Finland, we see COVID-19 soft law being used for the first time "to create new rules through a soft source", instead of (as in pre-pandemic times) being merely used as an interpretive aid. ${ }^{7}$

What these papers also show is a divergence in the hierarchy of norms used to respond to the current pandemic. Some countries already had in place legislation to respond to pandemics (and other emergencies), and used that legislation (eg Finland's Emergency Powers Act); in others, new hard laws were created (the Coronavirus Act 2020 in England, the widespread use of "Decree-Laws" in Italy, multiple "acts of legislative content" in Greece) or specific states of emergency (or alarm or danger) decreed under the relevant constitution or Basic Law (Spain, Hungary). In Germany and China we see existing laws, the Infection Protection Act and the Law on the Prevention and Treatment of Infectious Diseases respectively, modified to account specifically for the current crisis.

Questions as to legitimacy and accountability are frequent bedfellows for those doing work on soft law. ${ }^{8}$ The same is true of its use in this current crisis. There are, for instance, serious questions to be asked when soft law is created and deployed on a wide scale without parliamentary oversight or involvement (see the papers on the EU and on England). Participation is another common theme in soft law scholarship more generally and also in these Special Issue papers (see in particular those on the EU, China and Hungary). Publication practices for COVID-19 soft law also vary. This a matter of differences between jurisdictions and also a matter of differences within jurisdictions on pre-pandemic and pandemic practices. So, for example, in Spain, COVID-19 "soft law measures have been adopted in a rather informal way, in the sense that many of them have not been subject to official publication, but only published on the websites of the administrations that have created them". 9 This is

5 M Eliantonio and O Ştefan, "The Elusive Legitimacy of EU Soft Law: An Analysis of Consultation and Participation in the Process of Adopting COVID-19 Soft Law in the EU" (2021) European Journal of Risk Regulation <DOI:10.1017/err.2020.119>.

6 PL Láncos and L Christián, "Domestic Soft Law Regulation During the COVID-19 Lockdown in Hungary: A Novel Regulatory Approach to a Unique Global Challenge" (2021) European Journal of Risk Regulation <DOI:10.1017/err. 2020.115>.

7 E Korkea-aho and M Scheinin, “'Could You, Would You, Should You?' Regulating Cross-Border Travel Through COVID-19 Soft Law in Finland” (2021) European Journal of Risk Regulation <DOI:10.1017/err.2020.112>.

8 For a comprehensive literature review see O Stefan et al, EU Soft Law in the EU Legal Order: A Literature Review, in SoLaR Working Paper (2019) <ssrn.com/abstract=3346629>.

9 D Utrilla, "Soft Law Governance in Times of Coronavirus in Spain" (2021) European Journal of Risk Regulation $<$ DOI:10.1017/err.2020.117>. 
contrary to the only formal requirement in Spanish administrative law on non-binding measures: that they be published in the relevant official journal. In various jurisdictions, access to soft law measures on governmental and agency websites is not always straightforward (England, Finland, Hungary), and our contributors had problems establishing what soft law rules were in force and when and where to find them. In some cases, even the Wayback Machine, designed to dig out archived material from the world wide web, could not retrieve past soft law measures.

Another commonality in many of the legal systems we cover in this Special Issue is confusion on the part of the general public (and sometimes also on the part of the respective governments and their officials) as to how to view and/or respond to COVID-19 soft law and its relationship with COVID-19 hard law. This goes both to the nature of soft law and to the norms it creates. On the former, in Sweden, for example, the Director General of the Public Health Agency was quoted stating that General Recommendations are binding (when they are not; although the hard law onto which they are yoked is binding). And in Finland, the government's inexperience with soft law resulted in much confusion among the public and in public apologies from the ministry for the confusion. In England, the public was told that while "Public Health England recommends trying to keep $2 \mathrm{~m}$ away from people as a precaution" the next line in that guidance document says that "this is not a rule". ${ }^{10}$

Whether soft law is foreseen, whether it is created through express or implied powers (in constitutions or in other instruments) is a common concern of scholarship in this space. Who has norm-making competence and from where does that norm-making competence derive? It is not immediately clear, for example, on what (legal) basis the Hungarian National Education Authority recommendations were issued. The same is true in Germany with the national SARS-CoV-2 Occupational Safety Standard and various Federal Foreign Office travel warnings; with Finnish COVID-19 border control measures; and with local guidance in various parts of China on the wearing of masks. And yet the courts seem to have had little to say about the use of COVID-19 soft law. The Special Issue papers demonstrate that there are places in which there do not seem to have been any challenges to COVID-19 soft law (Sweden, Spain) and then places in which the courts have used COVID-19 soft law for a variety of purposes (in Spain, for example, to interpret existing hard law instruments against employers). In Finland, confusion over the government's guidelines and recommendations has not been commented upon by courts, but has led to various complaints to the Chancellor of Justice and the Parliamentary Ombudsman.

A number of the papers contained in this Special Issue also discuss the extent to which soft law is being used to interfere with the exercise of fundamental rights, and then the legality of such use. Of particular concern are restrictions on free movement (especially so in Finland, but also in Sweden), and as regards the processing of personal data (via virus contact tracing etc) (Greece, Hungary). In Italy, despite what the authors call "voluminous use of soft law", 11 COVID-19 soft law measures have not collided with fundamental rights. The same was reported in Spain. While the constitutional and legal limits of soft law seem to have been

\footnotetext{
10 Sorabji and Vaughan, supra, note 4.

11 F Aperio Bella et al, "The Role of COVID-19 Soft Law Measures in Italy: Much Ado about Nothing?" (2021) European Journal of Risk Regulation <DOI:10.1017/err.2020.116>.
} 
respected in general terms, our contributing authors call for caution. In Spain, for instance, the "widespread use of soft law measures as criteria justifying the adoption of binding measures restricting fundamental rights" 12 seems to be a growing trend and its consequences from the perspective of democratic accountability and judicial control of executive action should not be allowed to go unnoticed.

\section{Conclusions}

Is soft law pandemic-proof, suited to regulating risks? If we were to face another unknown deadly virus a decade from now - something we hope will not happen - would we then also turn to regulatory cocktails of General Recommendations, Protocols, Guidance, Technical Recommendations, Circulars, FAQs, Pandemic Plans, Administrative Directions, Codes of Conduct? Perhaps. There is no denying that COVID-19 soft law is soft law at its best: it is cheap, fast, flexible; and therefore good for emergency situations. But COVID-19 soft law is soft law also at its worst: it lacks democratic credentials, poses - unlike nonemergency soft law - risks for fundamental rights, results in constitutional encroachments, and confuses the general public.

What putting together this Special Issue has taught us (or reminded us) is that soft law is always a mix of these good and not-so-good elements. This is not to say that these not-sogood elements are inevitable, but to acknowledge that it is not possible to have the best of both worlds. It is hard to retain the speed and agility of soft law with parliamentary involvement or make full use of flexibility while also at the same time making the general public understand why soft law may be a rule or may not be a rule. The precise components of this regulatory response mix (what is non-negotiable and what can be compromised on) cannot be determined in abstract, in advance or uniformly across jurisdictions. Each jurisdiction must decide on its own smart mix. ${ }^{13}$ But these mixes are only smart if the decisions about them are informed and rely on data and research.

There is much more work that could be done in this space and we are struck by the lack of empirical work on soft law, ${ }^{14}$ particularly on how the general public perceives soft law and the norms it creates. In a number of the papers that follow (Sweden and China) our contributors note how high levels of public trust in the government tends to go hand in hand with high levels of compliance with COVID-19 measures. What is less clear, we think, is whether the general public follows soft law because they have faith in the government or whether they follow soft law because they think it imposes hard obligations on them (with sanctions for non-compliance). Similarly unclear is what drives national authorities to follow EU soft law or lower-level national authorities to follow soft law guidance adopted by hierarchically higher authorities. Answers to these questions and a better understanding of how citizens and authorities perceive soft law will hardly go to waste, although we hope this will be the last pandemic for some time.

\footnotetext{
12 Utrilla, supra, note 9.

13 For the idea, see J van Erp et al (eds), Smart Mixes for Transboundary Environmental Harm (Cambridge University Press 2019).

14 See for a recent exception, M Eliantonio et al (eds), EU Soft Law in the Member States: Theoretical Findings and Empirical Evidence (Hart Publishing 2021).
} 